\title{
Avaliação de Procedimentos Operacionais Padronizados Implementados na Produção e Manipulação de Fórmulas Infantis em Hospital Federal
}

\section{Standard Operating Procedures Evaluation Implemented in the Production and Manipulation of Infant Formulas in a Federal Hospital}

\author{
Maria das Graças Gomes de Azevedo Medeiros*a; Mariana Fernandes Garcia da Silva ${ }^{\mathrm{a}}$; Robson Maia Franco \\ Maria Carmela Kasnowski Holanda Duarte ${ }^{\mathrm{b}}$, Sergio Girão Barroso ${ }^{\mathrm{a}}$ \\ ${ }^{a}$ Universidade Federal Fluminense, Faculdade de Nutrição. RJ, Brasil. \\ bUniversidade Federal Fluminense, Programa de Pós-Graduação Stricto Sensu em Medicina Veterinária. RJ, Brasil. \\ *Email: mariadasmedeiros@id.uff.br
}

\begin{abstract}
Resumo
A contaminação de fórmulas infantis pode ocorrer quando os manipuladores cometem falhas operacionais ou por inadequações do ambiente de preparo. O objetivo da pesquisa foi avaliar a eficácia dos procedimentos operacionais padronizados executados na área de produção de fórmulas lácteas de um Hospital. Realizou-se uma pesquisa aplicada, descritiva e explicativa com avaliação do fluxo operacional e das condições físico funcionais, análise do comportamento dos manipuladores e pesquisas microbiológicas de Coliformes totais, Escherichia coli, Bactérias aeróbias mesófilas, Bacillus cereus, Yersinia enterocolitica, Listeria monicytogenes, Clostridium perfrigens, Clostridium Sulfito Redutor, Staphylococcus coagulase positiva, Salmonella spp., Enterococcous spp, Enterobacter sakazakii, Pseudomonas aeruginosa e fungos em superfícies de fórmulas infantis e água. Os procedimentos operacionais padronizados são executados em todas as etapas do processo, entretanto, foram observadas falhas humanas. Na avaliação físico-uncional, 92\% estavam em conformidade; na pesquisa microbiológica de superfícies, $12 \%$ de resultados deram presenças para Enterococcus spp., Coliformes totais, Escherichia coli e Bactérias heterotróficas aeróbias mesófilas. Nas fórmulas infantis, $8,33 \%$ dos resultados mostraram presença para Coliformes totais, Bactérias heterotróficas aeróbias mesófilas e Fungos. Os procedimentos implantados asseguram a qualidade sanitária das fórmulas, mas se verificou a necessidade de treina mento dos manipuladores.
\end{abstract}

Palavras-chave: Doenças Transmitidas por Alimentos. Fórmulas Infantis. Segurança Alimentar e Nutricional. Risco Sanitário.

\begin{abstract}
Infant formulas contamination may occur when handlers commit operational failures and or due to inadequacies in the staging environment. The objective of this research was evaluate the effectiveness of standard operating procedures performed in the production area of milk formulations of a Hospital. An applied, descriptive and explanatory research was conducted with evaluation of operational flow and physical functional conditions, analysis of the manipulators's behavior and microbiological investigations of MPN of total Coliforms, Escherichia col and Enterococcus spp., Count of Bacillus cereus/g, Clostridium sulfite reducer, molds and yeasts, Staphylococcus coagulase positive, aerobic mesophilic bacteria and Cronobacter sakazakii, research of Yersinia enterocolitica, Listeria monocytogenes, Salmonella spp and Pseudomonas aeruginosa on surfaces, infant formulas and water. Standard operating procedures were performed at all the process stages, however, human failures have been observed. In the physical functional evaluation, $92 \%$ was in compliance; on the surface microbiological analysis, $12 \%$ of the results present Enterococcus spp., Total Coliforms, Escherichia coli and aerobic mesophilic bacteria. In infant formulas, $8.33 \%$ results showed presence for Total Coliforms, aerobic mesophilic bacteria and Fungi. The implanted procedures assured the formulas sanitary quality, but the necessity of the manipulators's training was verified.
\end{abstract}

Keywords: Foodborne Diseases. Infant Formulas. Food and Nutrition Security. Health Risk.

\section{Introdução}

As fórmulas infantis (FI) são produtos destinados à alimentação de lactentes e crianças sadias ou enfermas, de acordo com a indicação de idade e de saúde (BRASIL, 2018) e se caracterizam como excelentes substratos para o desenvolvimento microbiano. A contaminação microbiológica pode ocorrer em diversas etapas do processo, sendo a manipulação uma etapa especialmente crítica (OMS, 2015).

Diversos estudos apontam a contaminação cruzada como uma das principais causas do crescimento microbiano em matrizes alimentares e como consequência os surtos de doenças alimentares (IVERSEN et al. 2004; SANTOS et al., 2015). As falhas nos procedimentos higiênico-sanitários são consideradas formas de disseminação de patógenos com graves riscos à contaminação de alimentos (FRANCO, 2012). O cuidado no preparo deste tipo de alimentação deve ser rigoroso, pois o público-alvo é suscetível a enfermidades e pode apresentar debilidade imunológica (ROSSI et al. 2010).

A Organização Mundial da Saúde (OMS) aponta a Enterobacter Sakazakii e Salmonella Enterica como patógenos cuja presença constitui risco de doenças grave e morte se contaminados por fórmulas infantis desidratadas, a partir de falhas do manipulador ou do ambiente do local 
de preparo (OMS, 2015). Na Instrução Normativa $n^{\circ} 60$, da Agência Nacional de Vigilância Sanitária - ANVISA (BRASIL, 2019) está prevista a pesquisa para Cronobacter spp, Enterobacteriaceae, Micro-organismos aeróbios mesófilos, Bacillus cereus e Salmonella sp em fórmulas infantis, a fim de mitigar o risco sanitário.

Apesar de não possuir legislação específica, na Resolução $n^{\circ} 63 / 2000$ consta a permissão do compartilhamento da área de preparo e envase de fórmulas lácteas com dietas enterais, desde que exista, por escrito, nos Procedimentos Operacionais Padronizados (POPs) e rotinas do serviço, horário distinto para as duas manipulações (BRASIL, 2000). Os POPs se apresentam como excelentes requisitos para o estabelecimento de padronização de processos e de medidas de controle, a fim de assegurar a qualidade microbiológica do alimento durante e ao final da cadeia produtiva (BRASIL, 2002).

Neste estudo se objetivou avaliar a eficácia dos procedimentos operacionais padronizados implantados na área de produção e de manipulação de fórmulas lácteas, no setor de Lactário/Enteral de um Hospital, relacionando-os com os aspectos construtivos e físicos funcionais, com o comportamento dos manipuladores durante as operações e com as análises microbiológicas das fórmulas infantis e das superfícies não biológicas.

\section{Material e Métodos}

A metodologia adotada foi aplicada de forma descritiva e experimental (GIL, 2011; MARCONI; LAKATOS, 2011). A pesquisa foi realizada no período de setembro de 2016 a junho de 2017 no Lactário/Enteral do Serviço de Nutrição de um Hospital Universitário do Estado do Rio de Janeiro e no Laboratório de Controle Microbiológico de Produtos de Origem animal (POA) da Faculdade de Veterinária da Universidade Federal Fluminense (UFF).

A metodologia foi constituída de duas partes: pesquisa bibliográfica e pesquisa de campo, dividida em três etapas de acordo com Marconi e Lakatos (2011). A pesquisa de campo compreendeu: aplicação da lista de checagem sobre as condições físico-funcionais; análise do fluxo operacional e pesquisa observacional das ações e comportamentos dos manipuladores, além das análises microbiológicas.

A lista de checagem utilizada foi adaptada de Medeiros (2014), baseado na RDC n 275/2002 (BRASIL, 2002). Foram avaliados aspectos constitutivos e de conservação dos equipamentos e utensílios utilizados na área pesquisada. Analisou-se o percentual de conformidade e a unidade foi classificada de acordo com a Resolução no 275/2002, da ANVISA (BRASIL, 2002).

$\mathrm{Na}$ pesquisa observacional se buscou analisar e comparar o fluxo operacional, com ações e comportamentos dos manipuladores com os POPs implantados. Utilizou-se um formulário com questões semiestruturadas aplicado na

forma de observação sistemática. Todas as ações foram identificadas e registradas durante a ocorrência (GIL, 2011).

As análises microbiológicas foram realizadas em duplicata e divididas em três etapas. A primeira etapa da pesquisa foi a coleta de amostras em superfícies de contato.

As amostras foram coletadas da balança (1 amostra), do passa prato de matéria-prima (1 amostra), do passa prato de produto final (1 amostra), das bancadas de manipulação A (2 amostras), da tampa e do fundo do interior da caixa de armazenamento de materiais estéreis (4 amostras) e das bancadas de manipulação B (2 amostras), totalizando 11 amostras. As análises microbiológicas realizadas foram de contagens de bactérias heterotróficas aeróbias mesófilas, Staphylococcus coagulase positiva, Número Mais Provável (NMP) de Enterococcous spp., Coliformes totais, Escherichia coli e pesquisa de Salmonella spp.. Na coleta de analitos de superfícies, os swabs foram imersos em solução salina peptonada a $0,1 \%$ contendo tiossulfato de sódio, após realizada a coleta do material para análise.

A segunda etapa da pesquisa compreendeu coletas e análises microbiológicas de fórmulas infantis (FI) identificadas como leites $\mathrm{X}, \mathrm{Y}$ e Z, em dois horários distintos: imediatamente após o preparo (tempo zero) e 24 horas após, acondicionadas em recipientes com tratamentos sanitários distintos (sanitização com hipoclorito de sódio a 1\% (T1) e a esterilização em autoclaves (T2)).

As análises microbiológicas das FI do Leite $\mathrm{X}$ e do Leite $\mathrm{Y}$ foram realizadas anteriormente ao treinamento de boas práticas dos funcionários. Por sua vez, as amostras da FI do Leite $\mathrm{Z}$ foram analisadas após o treinamento dos funcionários, o que permitiu avaliar a eficiência do treinamento e a influência na qualidade final do leite. Considerando-se dois momentos de coleta (tempo zero e 24 h) e dois tratamentos de higienização (T1 e T2) supracitados, foram analisadas quatro amostras para cada tipo de leite totalizando 12 amostras.

Para seleção das FI analisadas se utilizou o critério de maior consumo pelos pacientes internados no local da pesquisa, tendo características distintas: Leite $\mathrm{X}$ destinado aos recém-nascidos prematuros até o primeiro ano de vida, Leite Y destinado aos lactentes até os seis meses de vida e Leite Z, FI especial para crianças com alergias alimentares. As análises microbiológicas realizadas foram: NMP de Coliformes totais e Coliformes termotolerantes; Contagem de Staphylococcus coagulase positiva, Bacillus cereus, Cronobacter sakazakii, Clostridium sulfito redutor, Bactérias aeróbias mesófilas e fungos; pesquisa de Salmonella spp., Yersinia enterocolitica e Listeria monocytogenes.

Os resultados encontrados foram comparados ao padrão microbiológico determinado na Instrução Normativa 60/2019 para categoria alimentos infantis, especificamente, 
fórmulas infantis. Entretanto, na análise do NMP de Coliformes totais e Coliformes termotolerantes utilizou-se, para fins de comparação, a RDC 12/2001, pois a pesquisa é anterior à legislação atual, que não prevê este tipo de análise (BRASIL, 2001; BRASIL, 2019).

A terceira etapa da pesquisa foi a análise da água utilizada para o preparo das FI, com uma análise realizada anterior ao aquecimento da água para diluição das fórmulas e uma outra análise após o aquecimento da água. Realizou-se a Contagem de Bactérias heterotróficas aeróbias mesófilas viáveis $100 \mathrm{~mL}^{-1}$ pesquisa de Pseudomonas aeruginosa 100 $\mathrm{mL}^{-1}$ e NMP de Coliformes totais $100 \mathrm{~mL}^{-1}$. Utilizaram-se os padrões preconizados na Portaria 2914/ 2011 (BRASIL, 2011).

Nos dias de coleta se procedeu a análise observacional do processo de manipulação, ao longo da cadeia produtiva, em formulário estruturado com questões relativas aos POP aplicados e comportamentos do manipulador durante as atividades laborais.

Todas as amostras foram coletadas durante a realização do trabalho operacional, conforme metodologia proposta pelo Laboratório Central Dr Almino Fernandes (LACEN, 2010) e analisadas no Laboratório de Controle Microbiológico de Produtos de Origem Animal, do Departamento de Tecnologia de Alimentos da Faculdade de Veterinária/UFF.

As análises microbiológicas foram realizadas por metodologias analíticas específicas: NMP de Coliformes totais e Escherichia coli segundo Kornacki (2001); contagens de Bactérias Heterotróficas Aeróbias Mesófilas, contagem de Bacillus cereus, pesquisa de Yersinia enterocolitica e Listeria monocytogenes, contagem de Clostridium Sulfito Redutor (APHA, 2015) e contagem de fungos, conforme Salfinger e Tortello (2015); contagem de Staphylococcus coagulase positiva, baseado em Lancette e Bennett (2001); pesquisa de Salmonella spp. fundamentado em Andrews et al. (2011); NMP de Enterococcous spp. segundo Hartman et al. (2015) e contagem de Cronobacter sakazakii seguindo ISO/TS 22964 (2006) com modificações.

As temperaturas da unidade de frio utilizada para o armazenamento das FI foram registradas, no início das atividades laborais e no momento da coleta das amostras com 24 h após a produção, por meio de termômetro digital Interna 2070 x 0,1, marca Incoterm ${ }^{\circledR}$.

Para fins de análises estatísticas foi utilizado o teste exato de Fisher, para o cálculo das Razões de Chance de ocorrência de contaminação entre as duas etapas das análises microbiológicas e o Teste qui-quadrado para comparar os resultados microbiológicos obtidos entre as diferentes amostras (LEVIN, 1987). Em todas as análises, o nível de significância considerado foi de 5\%. Foi utilizado GraphPad Prim 5 para os cálculos estatísticos.

A pesquisa foi submetida ao Comitê de Ética em Pesquisa da Faculdade de Medicina - Hospital Universitário Antônio Pedro da Universidade Federal Fluminense, sob número CAAE 52648415.9.0000.5243.

\section{Resultados e Discussão}

O Padrão Operacional Padronizado estabelecido está sendo cumprido. O fluxo operacional está em conformidade com o descritivo técnico, as etapas previstas são realizadas de forma sequenciada e dentro dos prazos estabelecidos, técnicas de higiene foram cumpridas com rigor e foram realizados controles de tempo e temperatura.

Os resultados observados (Quadro 1) corroboram o relato de Steele e Short (2008), em que em sua pesquisa sobre FI, verificaram que quando preparadas ao lado do leito eram 24 vezes mais propensas a apresentar contaminação do que aquelas FI preparadas em centros específicos, como o Lactário. Além disso, as fórmulas em pó foram 14 vezes mais propensas a serem contaminadas do que as fórmulas prontas para consumo. A avaliação do local da preparação para verificar e corrigir erros é um fator importante para a qualidade do produto final, reduzindo a prevalência do crescimento microbiano (ROSSI et al., 2010).

Entretanto, em relação à análises de comportamentos foram constatados erros durante as atividades laborais, tais como: comunicação verbal durante o processamento, acionamento das fechaduras das portas das áreas internas do Lactário, com as mãos calçadas em luvas estéreis, sem troca ao retornar para o preparo da FI. A falta de luvas esterilizadas também foi observada durante o período de análise. Esses erros podem acarretar na contaminação das fórmulas através das mãos e fala entre os manipuladores.

Tartler e Fortuna (2012), em pesquisa microbiológica realizada em mãos e luvas de manipuladores de alimentos, identificaram a presença de coliformes totais em $41,35 \%$ das amostras analisadas, em que E. coli foi identificada em duas amostras de luvas, além disso foi avaliada a destreza dos manipuladores (canhotos ou destros), em que foi identificada a presença de maior contaminação nas mãos mais utilizadas, indicando possível contaminação cruzada pela falta de uma nova higienização, após contato com superfícies contaminadas. Na pesquisa realizada não foi observada a presença de E. coli em amostras de fórmula infantil, apesar de ser encontrada em $27 \%$ das amostras de superfícies, ou seja, em 3 (passa prato de material estéril e nas duas bancadas de manipulação) das 11 analisadas (Quadro 1).

Os resultados encontrados nas análises microbiológicas realizadas nas superfícies dos equipamentos estão apresentados no Quadro 1. 
Quadro 1 - Resultados das análises microbiológicas de swabs das amostras de superfícies

\begin{tabular}{|c|c|c|c|c|c|c|c|c|c|c|c|}
\hline & \multicolumn{7}{|c|}{ Coleta 1} & \multicolumn{4}{|c|}{ Coleta 2} \\
\hline Microrganismos & Balança & PPE & PPD & BM1 & BM2 & CT & CI & BM1' & BM2' & CT' & CI' \\
\hline $\begin{array}{c}\text { Sthapylococcus } \\
\text { Coagulase } \\
\text { Positiva (UFC/ } \\
\mathbf{c m}^{2} \text { ) }\end{array}$ & $\begin{array}{l}<10^{2} \\
\text { (est.) }\end{array}$ & $\begin{array}{l}<10^{2} \\
\text { (est.) }\end{array}$ & $\begin{array}{l}<10^{2} \\
\text { (est.) }\end{array}$ & $\begin{array}{l}<10^{2} \\
\text { (est.) }\end{array}$ & $\begin{array}{l}<10^{2} \\
\text { (est.) }\end{array}$ & $\begin{array}{l}<10^{2} \\
\text { (est.) }\end{array}$ & $\begin{array}{l}<10^{2} \\
\text { (est.) }\end{array}$ & $\begin{array}{l}<10^{2} \\
\text { (est.) }\end{array}$ & $\begin{array}{l}<10^{2} \\
\text { (est.) }\end{array}$ & $\begin{array}{l}<10^{2} \\
\text { (est.) }\end{array}$ & $\begin{array}{l}<10^{2} \\
\text { (est.) }\end{array}$ \\
\hline $\begin{array}{c}\text { Enterococcus } \\
\text { spp. }\left(\mathrm{NMP} / \mathrm{cm}^{2}\right)\end{array}$ & $<3$ & $<3$ & $<3$ & 16 & $>1100$ & $>1100$ & $<3$ & $<3$ & $<3$ & $<3$ & $<3$ \\
\hline Salmonella spp. & Ausência & Ausência & Ausência & Ausência & Ausência & Ausência & Ausência & Ausência & Ausência & Ausência & Ausênci \\
\hline $\begin{array}{c}\text { Coliformes } \\
\text { Totais } \\
\left(\mathrm{NMP} / \mathrm{cm}^{2}\right)\end{array}$ & $<3$ & $>1100$ & $<3$ & 160 & 1100 & $<3$ & $<3$ & $<3$ & $<3$ & $<3$ & $<3$ \\
\hline Escherichia coli & $<3$ & $>1100$ & $<3$ & 14 & 1100 & $<3$ & $<3$ & $<3$ & $<3$ & $<3$ & $<3$ \\
\hline $\begin{array}{c}\text { CBHAM } \\
\left(\mathrm{UFC}_{\mathrm{cm}^{2}}\right)\end{array}$ & $1,0 \times 10^{2}$ & $2,8 \times 10^{2}$ & $1,0 \times 10^{2}$ & $\begin{array}{c}7 \times 10^{0} \\
\text { (est.) }\end{array}$ & $\begin{array}{l}3 \times 10^{0} \\
\text { (est.) }\end{array}$ & $3,0 \times 10^{3}$ & $3,7 \times 10^{2}$ & $\begin{array}{l}<10^{1} \\
\text { (est.) }\end{array}$ & $\begin{array}{l}<10^{1} \\
\text { (est.) }\end{array}$ & $\begin{array}{l}<10^{1} \\
\text { (est.) }\end{array}$ & $\begin{array}{l}<10^{1} \\
\text { (est.) }\end{array}$ \\
\hline
\end{tabular}

PPE: Passa Prato de Material Estéril; PPD: Passa Prato de Distribuição; BM: Bancada de Manipulação; CT: Interior da tampa da caixa plástica de armazenamento de material estéril; CI: Interior do fundo da caixa plástica de armazenamento de material estéril. CBHAM: Contagem de Bactérias Heterotróficas Aeróbias Mesófilas.

Fonte: Dados da pesquisa..

O fluxo operacional é um fator importante com relação à contaminação cruzada, sendo recomendado pela RDC n 216 de 2004 (BRASIL, 2004) o fluxo ordenado e sem retrocessos ou cruzamentos na cadeia produtiva. O Lactário segue essa recomendação de entrada de materiais e saída do alimento pronto, por diferentes locais.

Quanto à avaliação físico-funcional, o Lactário/Enteral foi classificado no Grupo 1 tendo como base a Resolução $n^{\circ}$ 275/2002, da ANVISA (BRASIL, 2002), por ter apresentado um percentual de $92 \%$ de conformidade para os itens analisados durante a aplicação da lista de checagem. Os itens não conformes foram relacionados à conservação e as falhas na estrutura física. Em relação ao ambiente de preparo dos alimentos, esses se encontram dentro dos padrões recomendados previstos na Resolução n 63/2000 (BRASIL, 2000): revestimentos de material resistente aos agentes de limpeza e sanitização, área com dimensão suficiente para as operações com equipamentos organizados e em número suficientes, pisos e portas de fácil higienização e com proteção contra pragas, ausência de ralos abertos, iluminação adequada, entre outros. Foi observado também que a higiene do local está de acordo com os POPs estabelecidos.

As superfícies são higienizadas em conformidade com o POPs estabelecidos, porém a diferença entre os resultados nos dois dias de coleta foi consideravelmente relevante. Por meio da análise conjunta, microbiológica e a descrição dos procedimentos, é possível sugerir que o tempo entre a sanitização e o processamento é de extrema importância, visto que na segunda coleta, em que não houve resultados positivos para as análises microbiológicas realizadas, as amostras foram coletadas imediatamente após o procedimento higiênicosanitário.

Alguns resultados positivos podem estar relacionados à higiene pessoal dos manipuladores ou a infraestrutura do serviço. A contaminação no interior da tampa da caixa, utilizada para armazenar os materiais estéreis (Quadro 1), pode estar relacionada às falhas na higiene das mãos, uma vez que foi registrada, na análise observacional, que o utensílio é manipulado constantemente com as mãos sem luvas. Outro fator a ser considerado é a contaminação cruzada durante o processo, pelo fato da caixa armazenar material oriundo da central de esterilização do hospital, em sacos plásticos.

As elevadas contagens de Enterococcus spp. e coliformes totais observadas na bancada de manipulação devem ser consideradas como um importante fator de risco, uma vez que esses micro-organismos são indicadores de condições higiênico-sanitárias, empregados para avaliar a qualidade técnica dos produtos químicos utilizados no processo de higienização das superfícies (JAY, 2005).

Jay (2005), Franco e Landgraf (2005) esclareceram que no grupo de coliformes, a Escherichia coli se destaca por ser um indicador de contaminação fecal, em função de falhas ou erros em procedimentos higiênico-sanitários. A ingestão de alimentos contaminados por esta bactéria pode ocasionar a gastroenterite e, em casos mais graves, a colite hemorrágica, síndrome urêmica hemolítica e púrpura trombocitopênica. Considerando a premissa dos autores mencionados anteriormente e observando os resultados no Quadro 1, para a microbiota em questão, é necessário estar ciente da ocorrência dos micro-organismos na matriz alimentícia e em pontos de manipulação dos alimentos.

Similar ao estudo de Momesso et al. (2016), apesar de ter demonstrado FI aptas para consumo através de análises microbiológicas, identificou-se a presença significativa de bactérias aeróbicas mesófilas nos utensílios, tais como: colheres e liquidificadores, por meio de análise quantitativa. Em outro estudo de Rossi et al. (2010) foi encontrado um valor de $3,1 \times 10^{3} \mathrm{UFC} / \mathrm{cm}^{2}$, na contagem de bactérias aeróbias mesófilas em jarras plásticas utilizadas para preparação de FI, semelhante ao resultado encontrado no interior da tampa da caixa de materiais estéreis $\left(3,0 \times 10^{3} \mathrm{UFC} / \mathrm{cm}^{2}\right)$. Esses resultados revelam falhas na higiene e risco de contaminação 
cruzada, como identificado na maioria das análises das amostras da primeira coleta nesta pesquisa.

$\mathrm{Na}$ análise observacional, no primeiro dia de coleta, foram verificadas algumas falhas como: a falta de luvas estéreis; a comunicação entre funcionários e nutricionista, através do passa prato de material já preparado e durante a manipulação; a circulação de funcionários entre a sala de manipulação e a sala de apoio; e a não sanitização das mãos após o trânsito entre essas áreas. Esses comportamentos errôneos podem estar relacionados ao elevado número de coliformes totais encontrados no passa prato da matéria-prima (Quadro 1) e em um dos pontos analisados da bancada de manipulação. Em estudo no qual foram analisados vários trabalhos, que trataram da contaminação de alimentos com fortes evidências da transmissão de agentes etiológicos de doenças alimentares, por meio de contaminação cruzada, concluiu-se que a transmissão ocorre em decorrência de falhas no controle higiênico-sanitário (TOOD et al., 2009), como verificado durante a análise do comportamento de manipuladores.

$\mathrm{Na}$ análise da água utilizada para a diluição no preparo das FI, tanto antes do aquecimento (Coleta 1) quanto após o aquecimento (Coleta 2), não houve presença de nenhum dos micro-organismos pesquisados.

A World Health Organization (WHO, 2007), nas diretrizes para o preparo de FI, recomenda três formas principais para o preparo e manuseio deste alimento: diluir o leite em pó em água a uma temperatura de pelo menos $70{ }^{\circ} \mathrm{C}$ para inativar células da bactéria Cronobacter spp.; consumir o leite logo após cada preparação; e armazenar o leite reconstituído a $<5$ ${ }^{\circ} \mathrm{C}$. No Lactário, a água, além de ser filtrada, é aquecida até o ponto de ebulição $\left(100{ }^{\circ} \mathrm{C}\right)$, o que garante a sua segurança comprovada através das análises microbiológicas realizadas. Portanto, essa atende aos padrões microbiológicos previstos na Portaria 2914/ 2011 (BRASIL, 2011).

Quanto às FI analisadas, é possível afirmar que a amostra do Leite $\mathrm{X}$ atendeu aos padrões microbiológicos preconizados na Instrução Normativa n 60/2019 (BRASIL, 2019), entretanto, a amostra do Leite $Y$ se encontrou fora dos padrões para coliformes totais, apresentando uma contagem de 46 e 24 vezes maior do que a estipulada na RDC 12/2001 (BRASIL, 2001), em ambas as análises com material autoclavado, as amostras das fórmulas coletadas no tempo zero (imediatamente após o preparo) e com 24 horas preparadas, apresentaram contagens de coliformes totais de 460 e $240 \mathrm{NMP} / \mathrm{mL}$, respectivamente (Quadro 2). A presença de coliformes totais é indicativo de falhas ou ineficiência dos procedimentos higiênico-sanitários, durante o preparo das fórmulas, ou ainda, falhas na técnica utilizada para a autoclavagem do material de envase das fórmulas, uma vez que as amostras foram coletadas após o envase.

Quadro 2 - Resultados das análises microbiológicas das amostras dos Leites X e Y

\begin{tabular}{|c|c|c|c|c|c|c|c|c|}
\hline \multirow{3}{*}{ Microrganismos } & \multicolumn{4}{|c|}{ Leite $\mathbf{X}$} & \multicolumn{4}{|c|}{ Leite Y } \\
\hline & \multicolumn{2}{|c|}{$\begin{array}{c}\text { Materiais no Hipoclorito } \\
\text { a } 1 \% \\
\end{array}$} & \multicolumn{2}{|c|}{ Materiais autoclavados } & \multicolumn{2}{|c|}{$\begin{array}{c}\text { Materiais no Hipoclorito } \\
\text { a } 1 \% \\
\end{array}$} & \multicolumn{2}{|c|}{$\begin{array}{c}\text { Materiais } \\
\text { Autoclavados }\end{array}$} \\
\hline & $\mathbf{L X}^{\mathrm{HP}}$ & $\mathbf{L X}(24 h)^{\mathrm{HP}}$ & $\mathbf{L X}^{\mathrm{AC}}$ & $\mathbf{L X}(24 h)^{\mathrm{AC}}$ & LYHP & LY $(24 h)^{\mathrm{HP}}$ & LY'AC & $L Y(24 h)^{A C}$ \\
\hline $\begin{array}{c}\text { Coliformes totais } \\
(\mathrm{NMP} / \mathrm{mL})\end{array}$ & $<3$ & $<3$ & $<3$ & $<3$ & $<3$ & $<3$ & 460 & 240 \\
\hline E. coli $(\mathrm{NMP} / \mathrm{mL})$ & $<3$ & $<3$ & $<3$ & $<3$ & $<3$ & $<3$ & $<3$ & $<3$ \\
\hline $\begin{array}{c}\text { CBHAM } \\
\left(\mathrm{UFC}^{\left.-\mathrm{cm}^{2}\right)}\right.\end{array}$ & $1,0 \times 10^{1}$ & $2,3 \times 10^{4}$ & $<10^{1}$ (est.) & $<10^{1}$ (est.) & $1,0 \times 10^{1}$ & $\begin{array}{l}<10^{1} \\
\text { (est.) }\end{array}$ & $2,1 \times 10^{2}$ & $3,7 \times 10^{2}$ \\
\hline $\begin{array}{c}\text { Clostridium } \\
\text { Perfringens (UFC/ } \\
\mathbf{c m}^{2} \text { ) }\end{array}$ & $\begin{array}{l}<10^{1} \\
\text { (est.) }\end{array}$ & $\begin{array}{l}<10^{1} \\
\text { (est.) }\end{array}$ & $\begin{array}{l}<10^{1} \\
\text { (est.) }\end{array}$ & $\begin{array}{l}<10^{1} \\
\text { (est.) }\end{array}$ & $\begin{array}{l}<10^{1} \\
\text { (est.) }\end{array}$ & $\begin{array}{l}<10^{1} \\
\text { (est.) }\end{array}$ & $\begin{array}{l}<10^{1} \\
\text { (est.) }\end{array}$ & $\begin{array}{l}<10^{1} \\
\text { (est.) }\end{array}$ \\
\hline $\begin{array}{c}\text { Sthapylococcus } \\
\text { Coagulase Positiva } \\
\left(\mathrm{UFC}^{2} \mathrm{~cm}^{2}\right)\end{array}$ & $<10^{2}$ (est.) & $<10^{2}$ (est.) & $<10^{2}$ (est.) & $<10^{2}$ (est.) & $<10^{2}$ (est.) & $\begin{array}{l}<10^{2} \\
\text { (est.) }\end{array}$ & $<10^{2}$ (est.) & $<10^{2}$ (est.) \\
\hline $\begin{array}{l}\text { Bacillus cereus } \\
\left(\mathrm{UFC}^{\left.-\mathrm{cm}^{2}\right)}\right.\end{array}$ & $\begin{array}{l}<10^{1} \\
\text { (est.) }\end{array}$ & $\begin{array}{l}<10^{1} \\
\text { (est.) }\end{array}$ & $<10^{1}$ (est.) & $\begin{array}{l}<10^{1} \\
\text { (est.) }\end{array}$ & $\begin{array}{l}<10^{1} \\
\text { (est.) }\end{array}$ & $\begin{array}{l}<10^{1} \\
\text { (est.) }\end{array}$ & $\begin{array}{l}<10^{1} \\
\text { (est.) }\end{array}$ & $\begin{array}{l}<10^{1} \\
\text { (est.) }\end{array}$ \\
\hline $\begin{array}{c}\text { Yersinia } \\
\text { enterocolitica }\end{array}$ & Ausência & Ausência & Ausência & Ausência & Ausência & Ausência & Ausência & Ausência \\
\hline Salmonella spp. & Ausência & Ausência & Ausência & Ausência & Ausência & Ausência & Ausência & Ausência \\
\hline $\begin{array}{c}\text { Listeria } \\
\text { monocytogenes }\end{array}$ & Ausência & Ausência & Ausência & Ausência & Ausência & Ausência & Ausência & Ausência \\
\hline $\begin{array}{c}\text { Cronobacter } \\
\text { sakazakii }\end{array}$ & Ausência & Ausência & Ausência & Ausência & Ausência & Ausência & Ausência & Ausência \\
\hline $\begin{array}{c}\text { Fungos } \\
\left(\text { UFC/cm }^{2}\right)\end{array}$ & $<1$ & $<1$ & $<1$ & $<1$ & $1,5 \times 10^{1}$ & $3,3 \times 10^{3}$ & $8,4 \times 10^{3}$ & $1,7 \times 10^{3}$ \\
\hline
\end{tabular}

LX: Leite X; LY: Leite Y: com materiais sanitizados em solução de hipoclorito de sódio 1\%; AC: com materiais esterilizados em autoclave - CBHAM: Contagem de Bactérias Heterotróficas Aeróbias Mesófilas.

Fonte: Dados da pesquisa. 
Em pesquisa semelhante ao deste estudo, Rossi et al. (2010) obtiveram contaminação por Coliformes totais em 4 de 5 lotes de FI analisadas depois do envase, após 24 horas de refrigeração-em que os valores aumentaram ou se mantiveram, após o aquecimento - ocorrendo redução ou manutenção dos valores e após $2 \mathrm{~h}$ de distribuição - com grande variação de resposta relativa ao crescimento dos Coliformes totais. Como a redução, a manutenção ou o aumento do NMP de Coliformes totais não foi linear em todos os lotes é provável que houve a falta de padronização e controle do tempo e da temperatura de aquecimento da FI antes da distribuição. Esta falha também é sugerida, neste estudo, através do binômio tempo/temperatura da autoclave para os materiais utilizados no envase.

Aausência de Escherichia coli foi um resultado importante, pois sua presença indica contaminação com matéria fecal, que pode gerar sérios problemas de saúde pública, dependendo da patogenicidade da estirpe (SOUSA, 2006), principalmente, quando o público-alvo é considerado de risco, como na pesquisa desenvolvida.

Almeida et al. (1999), em pesquisa realizada no hospital na Bahia - Brasil, analisaram presença de micro-organismos como a $E$. coli em cinco ambientes diferentes de preparo de fórmulas infantis e das mãos de manipuladores, antes da aplicação do APPCC (Análise de Perigos e Pontos Críticos de Controle). Foi encontrada contaminação de $E$. coli em um dos ambientes de preparo e nas mãos dos manipuladores, que trabalhavam nesse mesmo ambiente, o que indica a contaminação cruzada e a importância da higiene dos manipuladores, cujas falhas destes afetam a qualidade do produto final.

De acordo com o estabelecido na legislação, o Leite $\mathrm{Z}$ se encontrou de acordo com os padrões legais vigentes, pois não apresentou crescimento de nenhum dos micro-organismos analisados, incluindo os previstos na Instrução Normativa ${ }^{\circ}$ 60/2019 (BRASIL, 2019).
Apesar de não existir padrões na legislação brasileira para Bactérias aeróbias mesófilas viáveis em FI, os resultados encontrados foram analisados levando-se em consideração os padrões microbiológicos para dietas enterais, visto que também são utilizadas em grupos de risco e, muitas vezes, em pacientes imunodeprimidos. Foi observada uma inadequação no Leite X, na análise de 24 horas com materiais sanitizados com solução de hipoclorito a 1\% (Quadro 2). A presença desses tipos de bactérias, apesar de não serem um indicador de segurança, por não estarem diretamente relacionadas à presença de patógenos ou toxinas, podem ser úteis, pois em altas concentrações, na avaliação da qualidade do produto, indica deficiências na sanitização ou falhas no controle dos processos (SILVA et al., 2017).

Em estudo realizado por Reginato et al. (2015) em que analisaram 26 amostras de fórmulas infantis, foram identificadas a presença de bactérias aeróbias mesófilas em $50 \%$ das amostras e $11,5 \%$ das amostras estavam inadequadas para o consumo por conter coliformes totais acima do limite indicado na Instrução Normativa $n^{\circ}$ 60/2019 (BRASIL, 2019), contra $17 \%$ das amostras analisadas no presente estudo, porém em ambas as pesquisas não foram identificadas contaminações por Staphylococcus coagulase positiva.

Não existe, na legislação brasileira, padrões definidos para as outras bactérias analisadas como o Clostridium perfringens, Yersinia enterocolitica, Listeria monocytogenes, Cronobacter sakazakii e para fungos, porém a realização da pesquisa é justificada pela debilidade imunológica do grupo, ao qual a matriz alimentícia analisada é destinada, em função da patogenicidade dessas bactérias e de algumas micotoxinas produzidas pelos fungos. Nos resultados obtidos, nenhuma das bactérias citadas foram isoladas diferentemente dos fungos em que se observou crescimento (Quadros 2 e 3).

Quadro 3 - Resultados das análises microbiológicas da amostra do Leite Z

\begin{tabular}{|c|c|c|c|c|}
\hline \multirow{3}{*}{ Micro-organismos } & \multicolumn{4}{|c|}{ Leite $\mathbf{Z}$} \\
\hline & \multicolumn{2}{|c|}{ Materiais no Hipoclorito a $1 \%$} & \multicolumn{2}{|c|}{ Materiais autoclavados } \\
\hline & $\mathbf{L} \mathbf{Z}^{\mathrm{HP}}$ & $\mathrm{LZ}(24 h)^{\mathrm{HP}}$ & $\mathbf{L Z}^{\mathrm{AC}}$ & $\mathbf{L Z}(\mathbf{2 4 h})^{\mathrm{AC}}$ \\
\hline Coliformes totais (NMP/mL) & $<3$ & $<3$ & $<3$ & $<3$ \\
\hline E. coli $(\mathrm{NMP} / \mathrm{mL})$ & $<3$ & $<3$ & $<3$ & $<3$ \\
\hline CBHAM (UFC/ $\left./ \mathrm{cm}^{2}\right)$ & $<10^{1}$ (est.) & $<10^{1}$ (est.) & $<10^{1}$ (est.) & $<10^{1}$ (est.) \\
\hline Clostridium Perfringens (UFC/cm²) & $<10^{1}$ (est.) & $<10^{1}$ (est.) & $<10^{1}$ (est.) & $<10^{1}$ (est.) \\
\hline Sthapylococcus Coagulase Positiva $\left(\mathrm{UFC} / \mathrm{cm}^{2}\right)$ & $<10^{2}$ (est.) & $<10^{2}$ (est.) & $<10^{2}$ (est.) & $<10^{2}$ (est.) \\
\hline Bacillus cereus $\left(\mathrm{UFC} / \mathrm{cm}^{2}\right)$ & $<10^{1}$ (est.) & $<10^{1}$ (est.) & $<10^{1}$ (est.) & $<10^{1}$ (est.) \\
\hline Yersinia enterocolitica & Ausência & Ausência & Ausência & Ausência \\
\hline Salmonella spp. & Ausência & Ausência & Ausência & Ausência \\
\hline Listeria monocytogenes & Ausência & Ausência & Ausência & Ausência \\
\hline Cronobacter sakazakii & Ausência & Ausência & Ausência & Ausência \\
\hline Fungos (UFC/cm²) & $<1$ & $<1$ & $<1$ & $<1$ \\
\hline
\end{tabular}

LZ: Leite Z;: com materiais sanitizados em solução de hipoclorito de sódio 1\%; AC: com materiais esterilizados em autoclave. CBHAM: Contagem de Bactérias Heterotróficas Aeróbias Mesófilas.

Fonte: Dados da pesquisa. 
Com relação à contagem de fungos, o crescimento no Leite Y $\left(1.5 \times 10^{1}, 3.3 \times 10^{3}, 8.4 \times 10^{3}\right.$ e $\left.1.7 \times 10^{3} \mathrm{UFC} / \mathrm{mL}\right)$ foi observado (Quadro 2), tanto nas coletas com materiais autoclavados quanto sanitizados com solução de hipoclorito a $1 \%$ e nos diferentes tempos (imediato ao preparo e $24 \mathrm{~h}$ após preparo), os resultados podem ser indicativos de contaminação ambiental e, consequentemente, a contaminação das fórmulas, uma vez que seus esporos podem permanecer no ar (FRANCO, 2012). Essa contaminação é considerada preocupante, porque os fungos e bolores durante o seu crescimento podem produzir microtoxinas, que são metabólitos tóxicos (SILVA et al., 2017).

Em estudo realizado por Mobin e Salmito (2006) se verificou a contaminação de condicionadores de ar em Unidades de Terapia Intensiva nos 10 aparelhos analisados, todos apresentaram contaminação fúngica, em que todas as espécies isoladas eram patogênicas. Uma vez que esse microorganismo pode se dispersar pelo ar, a análise no ambiente do lactário é fundamental para entender a presença e extensão de contaminação ambiental e seu efeito na produção das fórmulas.

$\mathrm{Na}$ análise das condições físico-funcionais do Lactário foram observadas pequenas rachaduras e presença de mofo no teto e no rejuntamento de alguns azulejos na área de preparo, resultados que podem ser associados às contaminações identificadas nas FI.

Após análise estatística que avaliou os resultados das diferentes técnicas de tratamento dos utensílios manipulados durante o preparo das fórmulas, desinfetados com hipoclorito de sódio diluído a $1 \%$ ou esterilizados em autoclave, é possível afirmar que não houve diferença estatística significativa ( $p$ > $0,05)$ para a contaminação, demonstrando que as duas técnicas podem ser utilizadas desde que corretamente, respeitando a diluição da solução de hipoclorito e o binômio tempo/ temperatura da autoclave.

Quanto às análises do Leite Z (Quadro 3), realizadas após o treinamento, todos os resultados foram negativos para os micro-organismos pesquisados. Como o intervalo de tempo entre a realização do treinamento dos funcionários responsáveis pela área do Lactário, em particular com os que manipulavam as fórmulas infantis, e a coleta do Leite Z, foi curto em relação às coletas das outras amostras, sendo sugerida a hipótese de que o treinamento frequente dos funcionários é indispensável para a melhoria da qualidade do produto final. $\mathrm{O}$ Leite $\mathrm{Z}$ não apresentou nenhum resultado positivo para os micro-organismos analisados, diferente dos outros leites, este apresentou resultado estatisticamente significativo com razão de chance 0,073 (IC 0,0042 - 1,28) e p = 0,0156. Portanto, é sugerida a hipótese de que o treinamento dos funcionários tenha auxiliado na correção das falhas higiênico-sanitárias e no aperfeiçoamento da técnica do processo do preparo das FI, com a melhoria da qualidade do produto final. A importância do treinamento de funcionários, que trabalham na manipulação de alimentos já foi comprovada em diversos estudos (MEDEIROS et al., 2017; SANTOS et al., 2015).

Este resultado corrobora aos obtidos por Silva e Santos (2015), que analisaram a qualidade microbiológica de mamadeiras de fórmulas lácteas antes e depois da implementação do sistema APPCC, obtendo 94,26\% de conformidade, após treinamento.

Os resultados microbiológicos positivos para o leite $\mathrm{Z}$ podem estar relacionados ao treinamento realizado em função das análises do leite $\mathrm{X}$ e Y. O processo de treinamento auxilia os funcionários a recordar a importância da utilização das boas práticas e necessidade do cumprimento dos Procedimentos Operacionais Padronizados.

Embora algumas análises tenham apresentado resultados positivos para os micro-organismos pesquisados, pela interpretação dos resultados estatísticos não se observou diferença significativa ( $p>0,05)$ entre os resultados obtidos nas manipulações, que foram realizadas com materiais sanitizados na solução do hipoclorito de sódio a $1 \%$ ou esterilizados em autoclave. Isso sugere que a contaminação encontrada não seja proveniente do modo de higienização dos utensílios e permite ao serviço a opção de escolha entre os dois métodos sem afetar a qualidade do produto final. Entretanto, faz-se necessário empreender esforços na ajuda sobre técnicas e metodologias de trabalho, a fim de corrigir falhas e mitigar problemas, com risco de saúde para os usuários do serviço.

\section{Conclusão}

Os Procedimentos Operacionais Padronizados previstos e implantados asseguram a qualidade sanitária das fórmulas infantis. Entretanto, com os resultados microbiológicos positivos se observa a necessidade de constante e sistemático treinamento dos manipuladores de alimentos do setor, a fim de que os erros sejam corrigidos e mitigados. Além disso, as técnicas de sanitização e/ou esterilização do material utilizado para armazenamento das fórmulas infantis precisam ser realizadas de forma correta para evitar contaminação cruzada, o que pode ter sido uma das causas da presença de coliformes totais no Leite $\mathrm{Y}$ envasado com materiais autoclavados. $\mathrm{O}$ binômio tempo e temperatura, assim como a manutenção constante dos equipamentos, podem ser eficazes na redução ou eliminação de falhas neste processo.

Os resultados da pesquisa podem servir como subsídio para a revisão dos padrões microbiológicos de alimentos, neste caso específico das fórmulas infantis para bebês até um ano ou prematuros, com a inclusão da pesquisa dos seguintes agentes etiológicos: Clostridium perfringens, Yersinia enterocolitica, Listeria monocytogenese, Cronobacter sakazakii, visto que em outros estudos também se concluiu a importância da pesquisa destes e os riscos para fins de saúde pública.

\section{Referências}

AMERICAN PUBLIC HEALTH ASSOCIATION - APHA. Compendium of methods for the microbiological examination of foods. Washington: APHA, 2015. 
ALMEIDA, R.C.D.C; MATOS, C.O.; ALMEIDA, P.F.D. Implementation of a HACCP system for on-site hospital preparation of infant formula. Food Control., v.10, n.3, p.181-187, 1999. doi: https://doi.org/10.1016/S0956-7135(99)00016-X

ANDREWS, W.H. et al. Salmonella. Compendium of Methods for the microbiological examination of foods. EUA: APHA, 2011, p. 357- 380 .

BRASIL. Resolução $n^{\circ}$ 63, de 06 de julho de 2000.. Requisitos de Boas Práticas de Funcionamento para os Serviços de Saúde, 2000.

BRASIL. Resolução no 12, de 02 de janeiro de 2001. Aprova o Regulamento Técnico sobre padrões microbiológicos para alimentos, 2001.

BRASIL. Agência Nacional de Vigilância Sanitária. Resolução $n^{\circ} 275$, de 21 de outubro de 2002. Regulamento Técnico de Procedimentos Operacionais Padronizados aplicados aos Estabelecimentos Produtores/Industrializadores de Alimentos e a Lista de Verificação das Boas Práticas de Fabricação em Estabelecimentos Produtores/Industrializadores de Alimentos, 2002.

BRASIL. Agência Nacional de Vigilância Sanitária. Resolução $n^{\circ} 216$, de 15 de outubro de 2004. Regulamento Técnico de Boas Práticas para Serviços de Alimentação, 2004.

BRASIL. Ministério da Saúde. Portaria 2914 de 12 de dezembro de 2011. Dispõe sobre os procedimentos de controle e de vigilância da qualidade da água para consumo humano e seu padrão de potabilidade. Brasília: MS, 2011.

BRASIL. Decreto 9579 de 22 de novembro de 2018. Consolida atos normativos editados pelo Poder Executivo federal que dispõem sobre a temática do lactente, da criança e do adolescente e do aprendiz, e sobre o Conselho Nacional dos Direitos da Criança e do Adolescente, o Fundo Nacional para a Criança e o Adolescente e os programas federais da criança e do adolescente, e dá outras providências, 2018.

BRASIL. Ministério da Saúde. Agência Nacional de Vigilância Sanitária. Instrução Normativa $n^{\circ} 60$ de 23 de dezembro de 2019. Estabelece as listas de padrões microbiológicos para alimentos. Brasília: MS, 2019.

FRANCO, B.G.M.; LANDGRAF, M. Microbiologia dos Alimentos. São Paulo: Atheneu, 2005.

FRANCO, R.M. Agentes etiológicos de doenças alimentares. Niterói: EDUFF, 2012.

GIL, A.C. Métodos e técnicas de pesquisa social. São Paulo: Atlas; 2011.

HARTMAN, P.A; DEIBE, R.H.; SIEVERDENZ, L.M. Enterococci. Compendium of Methods for the microbiological examination of foods. EUA: APHA, 2015. doi: 10.2105/MBEF.0222.015

INTERNATIONAL ORGANIZATION FOR STANDARTIZATION - ISO/TS 22964. Milk and Milk products - Detection of Enterobacter sakazakii. 2006.

IVERSEN, C.; LANE, M.; FORSYTHE, S.J. The growth profile, thermotolerance and biofilm formation of Enterobacter sakazakii grown in infant formula milk. Lett. Appl. Microbiol., v.38, n.5, p.378-382, 2004. doi: 10.1111/j.1472-765X.2004.01507.x

JAY, J.M. Microbiologia de alimentos. Porto Alegre: Artmed, 2005.

KORNACKI, J.L. Enterobacteriaceae, coliforms and Escherichia coli as quality and safety indicators. Compendium of methods for the microbilogical examination of foods. EUA: APHA, 2001.

LABORATÓRIO CENTRAL DR ALMINO FERNANDES (LACEN). Manual de coleta de amostras. Natal, 2010.

LANCETTE, G.A; BENNETT R.W. Staphylococcus aureus and staphylococcal enterotoxins. Compendium of methods for the microbiological examination of foods. EUA: APHA, 2001.

LEVIN, J. Estatística aplicada a ciências humanas. São Paulo, Harbra, 1987.
MARCONI, M.A.; LAKATOS, E.M. Técnicas de pesquisa. São Paulo: Atlas; 2011.

MEDEIROS M.G.G.A. Avaliação higiênico-sanitária em um restaurante universitário e proposição de um modelo operacional para o processamento da carne de frango em Unidades de Alimentação e Nutrição. Niterói: Universidade Federal Fluminense, 2014.

MEDEIROS, M.G.G.A; CARVALHO, L.R; FRANCO, R.M. Percepção sobre a higiene dos manipuladores de alimentos e perfil microbiológico em restaurante universitário. Ciênc. Saúde Coletiva, v.22, n.2, p.383-392, 2017.

MOBIN, M.; SALMITO, M.A. Microbiota fúngica dos condicionadores de ar nas unidades de terapia intensiva de Teresina, PI. Rev. da Soc. Bras. de Med. Trop., v.39, n.6, p.556-559, 2006. doi: 10.1590/S0037-86822006000600009

MOMESSO N.N. et al. Estudo da Contaminação Microbiana no Preparo de Fórmulas Lácteas Infantis em Lactário de um Hospital Universitário do Sul de Minas Gerais. Rev. Ciênc. Saúde, v.6, n.3, p.94-110, 2016. doi: 10.21876/rcsfmit.v6i3.581

ORGANIZAÇÃO MUNDIAL DA SAÚDE (OMS). Preparação, manipulação e conservação de fórmulas desidratadas para lactentes - Manual de boas práticas. Portugal: Instituto Nacional de Saúde Doutor Ricardo Jorge, 2015.

REGINATO, A. et al. Qualidade microbiológica de fórmulas infantis administradas em hospital público do município de Campinas, São Paulo. Segurança Aliment. Nutr., v.21, n.1, p.387394, 2015. doi: 10.20396/san.v21i1.1665

ROSSI, P.; KABUKI, D.Y.; KUAYE, A.Y. Avaliação microbiológica do preparo de fórmula láctea infantil em lactário hospitalar. Rev. Inst. Adolfo Lutz, v.69, n.4, p.503-509, 2010.

SALFINGER, Y.; TORTELLO, M. L. Compendium of Methods for the Microbiological Examination of Foods. Washington: APHA, 2015. doi: 10.2105/MBEF.0222.

SANTOS, A. C. S. et al. Microbiological quality of enteral feeding and infant formula produced in dietary units, according to the triado Donabedian. Nutr. Hosp., v.31, n.5, p.2122-2130, 2015. doi: 10.3305/nh.2015.31.5.8582

SILVA F.D.; SANTOS V.R.D. Qualidade microbiológica de mamadeiras de fórmula láctea antes e após a implantação do sistema de análise de perigos e pontos críticos de controle em lactário hospitalar. Rev. Hig. Alim., v.29, n.246/247, p.165-169, 2015.

SILVAN. D. et al. Manual de métodos de análise microbiológica de alimentos e água. São Paulo: Blucher; 2017.

SOUSA C.P. Segurança alimentar e doenças veiculadas por alimentos: utilização do grupo coliforme como um dos indicadores de qualidade de alimentos. Rev. A.P.S., v.9, n.1, p.83-88, 2006.

STEELE C.; SHORT R. Centralized infant formula preparation room in the neonatal intensive care unit reduces incidence of microbial contamination. J. Am. Dietetic Assoc., v.108, n.17001703, 2008. doi: 10.1016/j.jada.2008.07.009

TARTLER N.; FORTUNA J.L.; Qualidade microbiológica de mãos e luvas e avaliação higiênico-sanitária dos manipuladores de alimentos em uma praça de alimentação em Teixeira de FreitasBA. Rev. Bras. Ciênc. Vet., v.19, n.2, p.104-108, 2012.

TOOD E.C. et al. Outbreaks where workiers have been implicated in the spread of foodborne disease. Part 6. Transmission and survival of pathogens in the food processing and preparation environment. J. Food. Protect., v.72, n.1, p.202-219, 2009.

WHO - World Health Organization. Safe preparation, storage and handling of powdered infant formula, United States, 2007. 